Fecha de recepción: noviembre 2018 Fecha de aceptación: marzo 2019 Versión final: julio 2019

\section{Las editoriales universitarias de cara a los procesos de internacionalización de la educación superior: El caso de las políticas editoriales de EDUNTREF entre 2011-2017}

Ana Verdelli ${ }^{\star}$

\begin{abstract}
Resumen: El presente trabajo explora las políticas editoriales de la Editorial de la Universidad de Tres de Febrero (EDUNTREF) y, dentro de éstas, hace foco en las políticas de traducción y sus vinculaciones con la actividad universitaria local e internacional de la UNTREF. Para ello, se ha trabajado con dos fuentes de datos: los catálogos de publicaciones del período 2011-2016 y una entrevista en profundidad a su directora editorial. Los resultados obtenidos permiten delinear las principales características y políticas de la editorial (siguiendo a de Sagastizábal, 2006) y nos invitan a reflexionar acerca del papel de la editorial como agente democratizador del conocimiento en el marco del proceso de internacionalización de la Universidad.
\end{abstract}

Palabras clave: Editoriales Universitarias - Política de Edición - Traducción - Catálogos Internacionalización - Educación Superior.

[Resúmenes en inglés y portugués en la página 84]

(*) Licenciada en Ingles (Universidad Nacional del Litoral) y Especialista en Gestión de Lenguas (Universidad Nacional de Tres de Febrero). Profesora en Inglés (ISP "Dr. J. V. González"). Sus áreas de investigación principales son las políticas lingüísticas en el nivel superior (SID UNTREF) y la formación inicial de docentes de inglés (INFD, UIDI ISP "Dr. J. V. González"). Se desempeña como docente en el área de Lingüística en la ENSLV "Sofía E. B. de Spangenberg". anamerv@yahoo.com.ar

\title{
Introducción
}

Las editoriales universitarias constituyen el punto de encuentro entre dos mundos: el de la universidad y el del libro. Dado que su objetivo primero es el de complementar las tres funciones misionales de la educación superior (docencia, investigación y extensión), sus políticas editoriales deben ser entendidas a la luz de las necesidades de la academia y de la comunidad en la cual la universidad está inserta. En este sentido, Jorge Salazar Ferro sostiene que este tipo de actividad editorial no debe pensarse como "algo aleatorio a la universidad, sino por el contrario, como un quehacer que se desprende de su misma misión 
fundamental de producción y transmisión del conocimiento" (1991, en De Sagastizábal, Rama y Uribe, 2006, p. 41).

La Editorial de la Universidad de Tres de Febrero (de aquí en adelante, EDUNTREF) es un claro exponente de esta estrecha vinculación con la institución madre. En las palabras introductorias de los catálogos, el rector Anibal Jozami presenta a la editorial como un espacio de difusión de los trabajos producidos en la Universidad:

Cada obra de nuestra editorial es el fruto de los equipos de trabajo académico y la dirección de investigadores que habitualmente participan de los foros mas importantes de su área disciplinar a nivel mundial...Los títulos que aquí presentamos indican las áreas prioritarias del trabajo articulado de docencia, investigación y extensión. Son el punto de partida y el indicador de nuestro avance en el proceso de producción de conocimiento propio (Catálogo EDUNTREF, 2016, p. 3).

La referencia que hace Jozami a los foros mundiales no es casual. La UNTREF le asigna un lugar relevante al proceso de internacionalización, tanto de sus carreras de grado como de posgrado y trabaja activamente en pos de su proyección externa a través de su Dirección de Cooperación Internacional, por medio de la cual se han firmado convenios entre universidades, establecimientos educativos y centros de investigación de distintos países. De acuerdo al último Informe de Gestión publicado (2015)릴 la Universidad recibió 83 estudiantes de diferentes nacionalidades en sus programas de posgrado (especializaciones, maestrías y doctorados) que se sumaron a otros estudiantes extranjeros que llegaron por medio de convenios bilaterales o becas.

Si hablamos de internacionalización de la educación superior, entendida como el "proceso de integrar una dimensión internacional e intercultural a las funciones de enseñanza, investigación y servicio de la institución" (Knight, 2005, p. 7), es necesario mencionar los dos paradigmas que están hoy en discusión: uno que nace con el proceso de Bolonia (1999) y se caracteriza por tender hacia la mercantilización de servicios educativos, y otro, más reciente, plasmado en la Declaración de Cartagena (IESALC-UNESCO, 2008) que entiende la internacionalización como motor de una política educativa pública orientada a fortalecer la oferta académica y el desarrollo científico-tecnológico.

Cada uno de estos modelos tiene su correlato en el mundo editorial universitario. Carlos Gazzera, ex coordinador de la REUN (Red de Editoriales de Universitarias Nacionales), explica que:

En el mundo de la Edición esta dicotomía [Bolonia vs. Cartagena] se expresa entre los que creen que la Universidad debe prestar un servicio con sus publicaciones y los que sostienen que la inclusión pasa por un rol de la Editorial Universitaria como garante de la bibliodiversidad e inclusivo con el lector (Gazzera, 2014, p. 63).

Los dos modelos se pueden leer también como extremos en un continuo de perfiles editoriales: desde una editorial enfocada en ofrecer un servicio a los académicos 'de la casa' (con 
el consiguiente acceso al preciado ISBN, mediado por el juicio de pares y no por la evaluación de un comité editorial) hasta una editorial preocupada por satisfacer las demandas de estudiantes y docentes, pero también vinculada con los intereses de la comunidad toda (nacional e internacional), a través de la publicación de obras de investigación académica y de divulgación.

Ahora bien, dijimos que en las editoriales universitarias confluye el mundo universitario, del que ya hemos dado breve cuenta, y el del libro. A la tensión entre la mercantilización y la democratización del saber que hemos referido se suma entonces la dualidad constitutiva del libro que señala Pierre Bourdieu: "el libro, objeto de doble faz, económica y simbólica, es a la vez mercancía y significación" (1999, p. 242). Si bien en ambos campos emerge la tensión entre el valor cultural y el valor comercial, postular un paralelismo entre ellos en el caso específico de las editoriales universitarias sería engañoso. Cuando las editoriales universitarias construyen su catálogo con una lógica en la que "el beneficio económico está subordinado a la acumulación de capital simbólico" (Stukalsky y Gazzera, 2013, p. 4), las obras que son publicadas apuntan a satisfacer principalmente las demandas del mercado académico en el cual circulan. Por el contrario, aquellas editoriales universitarias que también tienen en cuenta la rentabilidad -reduciendo sus tiradas, editando más y variados títulos, generando nuevos mecanismos de distribución y circulación, digitalizando sus catálogos-, logran alcanzar nuevas audiencias, lo que resulta en una mayor difusión del capital simbólico.

A la luz de lo expuesto, nos preguntamos de qué manera EDUNTREF se vincula con la actividad universitaria local e internacional de la UNTREF. Para dar respuesta a esta pregunta se explorarán sus políticas editoriales, es decir, el "conjunto de elecciones y estrategias adoptadas por los agentes editoriales... sobre la base de objetivos y valores, los cuales pueden ser culturales, políticos y/o económicos" (Sapiro, 2010, p. 32). Dentro de éstas, se le prestará particular atención a las políticas de traducción, entendidas como "todas las formas institucionales de decisión sobre lo que se traduce" (Willson, 2013, p. 89). Si bien la naturaleza de este trabajo es de índole exploratoria/descriptiva, se parte del supuesto de que EDUNTREF tiene una política editorial propia, así como una política respecto a la traducción de las obras que integran su catálogo, aunque no está debidamente explicitada. Para reconstruir dichas políticas editoriales se han utilizado dos fuentes de datos. En una primera instancia se trabajó con los catálogos correspondientes al período 2011-2016 para analizar las obras que componen el fondo editorial, las áreas temáticas, los autores y las publicaciones traducidas. Luego, se contactó a la directora editorial de EDUNTREF, María Inés Linares, a quien se entrevistó personalmente para indagar con mayor profundidad acerca de los criterios y las decisiones que han dado forma al catálogo. Los resultados obtenidos y su discusión se presentan en dos apartados: una caracterización general de las políticas editoriales de EDUNTREF, seguida de una sección dedicada a sus políticas de traducción. Finalmente, estos datos se pondrán en relación con el papel de la editorial en el marco del proceso de internacionalización de la Universidad. 


\section{Características de la editorial}

Comencemos por describir los rasgos salientes que caracterizan la actividad editorial de EDUNTREF. Para ello, seguiremos la taxonomía diseñada por De Sagastizábal para el estudio comparativo de editoriales universitarias (De Sagastizábal, Rama y Uribe, 2006).

\section{a. Autonomía financiera y editorial.}

Los recursos financieros de la editorial dependen exclusivamente de la Universidad, lo cual incluye el pago de costos fijos, la producción y la comercialización de las publicaciones y hasta la caja chica. De Sagastizabal advierte que en casos de escasa autonomía financiera, "es poco factible que una editorial se rodee de personal idóneo, profesionalizado, si no cuenta con la mínima independencia para definir su planta de empleados. Del mismo modo, la contratación de proveedores externos... estará totalmente restringida y condicionada" (Ibíd., p. 111). Si bien no pareciera haber dudas acerca de la idoneidad de los empleados y proveedores de EDUNTREF, sí es cierto que varios de ellos no son exclusivos de la editorial, sino que trabajan para la Universidad en su conjunto, con lo cual las tareas editoriales se suman a una larga lista de otras demandas. Tal es el caso del coordinador gráfico, quien se encarga de la gráfica de toda la Universidad, y del estudio de diseño contratado, que además de trabajar para la editorial produce las piezas gráficas que la Universidad requiere (folletería, señalética, carteles de las muestras, etc.).

Asimismo, el grado de autonomía editorial depende en gran medida de la autonomía financiera, ya que "el modo de obtención de los recursos para la producción de libros... puede condicionar la elección de los originales que se editen" (Ibíd., p. 111). En este sentido, la directora editorial explica actualmente que los proyectos que se presentan son evaluados en forma conjunta entre ella y el vicerrector. Sin embargo, hasta abril de 2016 EDUNTREF no contaba con una figura de director editorial, con lo cual todas las decisiones editoriales pasaban exclusivamente por el vicerrector. Si bien la nueva estructura ya tiene más de un año de antigüedad, la directora señala que el cambio aún no ha sido asimilado por algunos autores: "A veces los autores directamente van [al vicerrector], porque hay gente que todavía no me conoce" (M. I. Linares, comunicación personal, 8 de mayo de 2017). Tras comparar diversas editoriales universitarias, De Sagastizábal concluye que este tipo de dinámicas entre los autores 'de la casa' y las autoridades son bastante comunes: "Con frecuencia algunos autores con una prestigiosa carrera académica recurren a sus vinculaciones dentro de la universidad para obtener el aval que dé vía libre a la publicación de su obra" (Ibíd., p. 111). En un esfuerzo por ajustar la lógica académica a la lógica editorial, se ha implementado un formulario que los autores deben completar al presentar un manuscrito. En esta propuesta, se debe explicitar el público al que la obra va dirigida, si es necesario traducirla o si lleva imágenes ( $y$ en ese caso, si hay que adquirir los derechos de las mismas). Incluye también un resumen del texto, un índice y un esquema de su estructura. Se trata, en suma, de una herramienta de evaluación formal, un paso intermedio para examinar la pertinencia de los manuscritos, que determina su publicación. La editora se afirma así en su rol de mediadora entre los autores y sus manuscritos, y la producción final del libro. 


\section{b. Tipo de estructura.}

La manera en la que se trabaja en una editorial universitaria está condicionada por su estructura, que determina tanto su funcionamiento interno como su producción editorial. Las editoriales universitarias pueden depender de diversos departamentos, secretarias, o, como en el caso de EDUNTREF, directamente del Rectorado. Por eso el estrecho vínculo laboral entre la directora editorial y el vicerrector ya referido.

En términos de tamaño, se trata de una editorial muy pequeña que ni siquiera cuenta con un espacio físico propio. Su plantel es extremadamente reducido, al igual que en la mayoría de las editoriales universitarias de la Argentina (De Sagastizábal, Rama y Uribe, 2006). Se compone de cuatro personas: una directora editorial, un coordinador editorial que se encarga de la producción, un coordinador gráfico (quien, como hemos mencionado, se encarga de la gráfica de toda la Universidad) y un encargado de distribución. Las tareas de diseño gráfico y la elaboración de los catálogos de arte (producidos por un equipo que depende directamente de la directora del Instituto de Investigaciones en Arte y Cultura) son encomendadas a estudios externos. La editorial también trabaja coordinadamente con la biblioteca de la Universidad. La directora de la biblioteca y su asistente son las encargadas del stock, ya que el depósito se encuentra en la biblioteca.

Siendo una estructura tan pequeña, no hay una tajante división de tareas. Al momento de la entrevista, por ejemplo, se estaba organizando un nuevo sistema de distribución que era coordinado por el encargado de distribución, pero también por el coordinador gráfico. La directora editorial también relata que hasta su llegada, el coordinador editorial tenía a su cargo múltiples tareas:

Si bien la editorial empezó en 2001, hasta ahora la venía coordinando [el coordinador editorial]. Pero era una sola persona para todo: tanto para las cosas que son específicamente del trabajo con los libros como para todo lo que es externo --el trato con los autores, la gestión de derechos... Era abrumador (entrevista a directora editorial Linares, 2017).

Otro aspecto insoslayable en esta caracterización es que EDUNTREF carece de un comité o consejo editorial. Esto es un asunto que preocupa a la directora, quien ha manifestado la necesidad de su creación para poder evaluar las propuestas de los autores con mayor objetividad y experticia:

La realidad es que objetivamente ni [el vicerrector] ni yo conocemos sobre todas las áreas de conocimiento que se pueden publicar en la editorial. Lo ideal sería tener un comité de especialistas, aunque sea uno por cada área o disciplina, para evaluar los proyectos que se presentan (entrevista a directora editorial Linares, 2017).

En suma, si pensamos en términos de estructura y autonomía, EDUNTREF se encuentra a mitad de camino entre las editoriales con máxima independencia (por ejemplo, EUDEBA) y aquellas que son apenas un poco más que oficinas de publicaciones e impresiones. 
En relación con otras editoriales universitarias del país y la región (ver De Sagastizábal, Rama y Uribe, 2006), comparte las características de tamaño y la superposición de tareas y responsabilidades. Se distingue, sin embargo, por la capacitación específica y profesionalización del personal directivo, que no es un rasgo común en las editoriales de su tipo.

\section{c. Producción bibliográfica.}

Se desprende del análisis de los catálogos editados entre 2011 y 2016 que EDUNTREF cuenta con un fondo editorial conformado por 138 títulos, organizado en diversas colecciones que se han ido reformulando y reagrupando año tras año. Las más prolíficas (aquellas con 10 títulos o más) son Arte y Cultura (21 títulos), Educación y Política Educativa (16), Historia del Peronismo (15), Ciencias Sociales, Política y DDHH (12), Historia Cultural (12) y Relaciones Internacionales y Administración (10). Las 12 colecciones restantes no superan los cuatro títulos cada una. Respecto a las líneas temáticas, De Sagastizábal sostiene que "están definidas por el carácter de las instituciones y que generalmente hay una correspondencia entre las publicaciones y las áreas prioritarias de desarrollo de las casas de estudio" (2006, p. 150). En el caso de EDUNTREF, las colecciones con más publicaciones están estrechamente relacionadas con institutos de investigación especializados que funcionan en el seno de la Universidad (por ejemplo, el Centro de Investigación en Arte, Materia y Cultura o el Programa de Estudios de Historia del Peronismo).

Un aspecto interesante para analizar de la producción bibliográfica es la nacionalidad de los autores. En la siguiente tabla podemos ver como se distribuyen las obras que componen el fondo editorial de acuerdo a las distintas áreas temáticas en que está organizado el catálogo y la nacionalidad de sus autores:

Tabla 1: Cantidad de obras por área temática y nacionalidad de los autores

\begin{tabular}{|l|c|c|l|}
\hline Área temática & Argent. & Extran. & $\begin{array}{l}\text { Nacionalidad de los autores } \\
\text { extranjeros }\end{array}$ \\
\hline Antropología & 1 & 0 & \\
\hline Arte y cultura & 16 & 4 & $\begin{array}{l}\text { Franco-canadiense, } \\
\text { norteamericanos (3) }\end{array}$ \\
\hline Bioacústica y Medio Ambiente & 2 & 0 & \\
\hline Cinematografía & 3 & 2 & Cubano, norteamericano \\
\hline Comunicación & 2 & 0 & \\
\hline Cs. Sociales, Política y DDHH & 10 & 1 & Polaco \\
\hline Derecho Int. y Relaciones Int. & 2 & 1 & Polaco \\
\hline
\end{tabular}

continúa $>>$ 


\begin{tabular}{|c|c|c|c|}
\hline Economía & 2 & 0 & \\
\hline Educación y Política Educativa & 14 & 3 & Brasileña, español y franceses (2) \\
\hline Filosofía / Psicología & 4 & 3 & Franco-canadiense (3) \\
\hline Historia Cultural & 12 & 0 & \\
\hline Historia de la Ciencia & 4 & 0 & \\
\hline Historia del peronismo & 11 & 4 & $\begin{array}{l}\text { Alemán, israelí, italiano y } \\
\text { norteamericano }\end{array}$ \\
\hline $\begin{array}{l}\text { Historia Económica e } \\
\text { Historiografía }\end{array}$ & 2 & 1 & Norteamericano \\
\hline Informática & 1 & 0 & \\
\hline Literatura gauchesca & 2 & 0 & \\
\hline Relaciones Int. y Administración & 8 & 2 & Francés (2) \\
\hline Teoría Literaria & 2 & 2 & Alemán e italiano \\
\hline Coediciones PROMETEO & 2 & 15 & $\begin{array}{l}\text { Alemán, argentino-israelí, } \\
\text { australiano, canadiense, francés, } \\
\text { norteamericano, polaco, uruguayo }\end{array}$ \\
\hline TOTAL & 100 & 38 & \\
\hline
\end{tabular}

Como podemos apreciar, dejando de lado las publicaciones que se editaron en conjunto con Prometeo, UNTREF ha publicado 23 trabajos de autores extranjeros. Aquellas áreas de conocimiento en las que se registra mayor participación de autores extranjeros son las artes (arte, cultura y cinematografía), las humanidades (filosofía, psicología y teoría literaria) e historia del peronismo. En el resto de las ciencias sociales (antropología, comunicación, política, derecho, economía, educación, e historia) casi no hay lugar para otras voces que no sean locales. Respecto a las nacionalidades de los autores, se observa una mayor presencia de escritores europeos (autores de 10 obras) y norteamericanos (de 6), mientras que los autores latinoamericanos son apenas dos (y en un caso, la obra es en co-autoría con un argentino) y no hay ninguna obra escrita por autores asiáticos o africanos.

En relación a las tiradas, EDUNTREF solía imprimir 1.000 ejemplares de cada libro o revista -el doble del promedio en el país (ver De Sagastizábal, Rama y Uribe, 2006), pero la nueva gestión editorial ha implementado una reducción en las tiradas, especialmente en el caso de las publicaciones periódicas ${ }^{2}$, de las cuales actualmente se hacen tiradas de 100-200 ejemplares. Esta decisión, explica Linares, resulta de aplicar una lógica editorial a la preexistente lógica académica pura: 
Hay casos en los que realmente no se vende el libro, y no porque sea malo, sino porque no hay tanta gente para leerlo. Ahora teniendo las posibilidades de impresión sobre demanda, que uno puede elegir imprimir menos y no es tan caro como antes. Pensar un poco más las tiradas antes de imprimir te da un poco más de margen y no te hace acumular stock inútilmente (entrevista a directora editorial Linares, 2017).

La cuestión de la falta de público lector para una obra que plantea Linares es señalada por De Sagastizábal como el principal impedimento que tiene un texto para convertirse en libro: "muchos de los libros no son leídos por el simple hecho de que no fueron pensados para ser leídos...no vienen a satisfacer ningún deseo ni necesidad de sus lectores, no cubren necesidades formativas, ni instrumentales, ni intelectuales (Ibíd., p. 147)".

La tensión entre los criterios académicos y editoriales es característica de las editoriales universitarias de la región, pero EDUNTREF pareciera estar en la búsqueda de conciliar ambas lógicas. La directora editorial cree que si los libros pudieran llegar a librerías del circuito comercial, hay un público lector potencial que puede verse atraído por aquellos que no son estrictamente académicos:

Hasta ahora [el catálogo] venía bastante orientado a público académico, relacionado con la universidad. Pero hay algunos títulos que tienen un campo más amplio... Lo mismo los catálogos de arte, que pueden resultar de interés a cualquiera que va a una muestra, o algunos títulos de divulgación... que está[n] escrito[s] específicamente pensando en un lector no académico (Linares, 2017).

Además de impulsar los títulos de divulgación, la inclusión de literatura en el catálogo (narrativa y poesía) es otra de las estrategias que la directora editorial tiene en mente para captar nuevos lectores.

\section{d. Relación con los autores.}

La decisión de formalizar los requisitos de presentación de los manuscritos mencionada anteriormente responde a la necesidad de renovar ciertas prácticas características de las editoriales universitarias que tiene lugar principalmente cuando los textos son presentados por investigadores y profesores de la propia Universidad. En el vínculo entre la editorial y los autores se da lo que De Sagastizábal ha dado en llamar "una confusión entre la política educativa y la gestión de influencias dentro de la universidad, y las políticas editoriales" (Ibíd., p. 145): por un lado, los autores 'de la casa' sienten que la editorial tiene la obligación de publicar sus obras, y suelen apelar al respaldo de las autoridades al presentar sus manuscritos. Los editores, por su parte, suelen carecer de la autonomía necesaria para resistir las presiones internas, con lo cual es muy difícil que puedan rechazar estos originales, especialmente si se trata de textos que gozan con el necesario aval científico-académico. Lo que suele quedar relegado entonces es el criterio editorial puro: $i$ se adecuan las propuestas al catálogo?, ¿existen lectores suficientes para justificar la impresión de esa obra? 
Lejos de tomar partido por una lógica u otra, la directora editorial insiste en que el éxito de una editorial universitaria depende precisamente en armonizar las dos dimensiones:

Está la creencia de que pensar en las ventas es contaminarse: 'nosotros somos académicos, ¿cómo vamos a pensar en vender?'. Pero la realidad es que, si vendemos. nos sostenemos mejor y podemos publicar más libros. No está mal pensar que el libro se venda. Y no está mal pensar un poco mejor la política de tiradas: cuánto imprimimos de cada título, pensar cuánto se va a vender (Linares, 2017).

Incluir criterios comerciales significa también permitirse repensar el soporte del libro (papel o electrónico) y su distribución.

\section{e. Distribución y ventas.}

Actualmente, los títulos se pueden conseguir en cuatro sedes: una librería propia en CABA y otros tres puntos de venta instalados en dependencias de la Universidad (en el campus de Caseros, en la sede de posgrados en el C. C. Borges y en el Museo de la Inmigración y Centro de Arte Contemporáneo). Anteriormente, Ediciones Prometeo se encargaba de la distribución, pero desde mediados de 2016, EDUNTREF comenzó a implementar un sistema propio. Uno de los objetivos del nuevo sistema de distribución es precisamente trascender el circuito universitario para desembarcar en las librerías comerciales, y así, agrega la directora, llegar a nuevos lectores: "la idea es que se sume público que no necesariamente sea de la universidad” (Linares, 2017).

Otra dimensión en relación a las ventas es la posibilidad de comprar los libros en el exterior. La directora explica que la editorial aún no cuenta con una distribución organizada fronteras afuera, y que los libros que circulan en otros países son trasladados por sus propios autores cuando éstos viajan: "los libros llegan al exterior porque los autores tienen contactos con académicos de otras universidades y se van intercambiando los libros, a través de los congresos, o por intercambios con bibliotecas" (Linares, 2017).

Dadas las limitaciones económicas que tiene una editorial pequeña como EDUNTREF, la alternativa para no descartar los mercados externos parece estar en cambiar el soporte del libro. Linares explica que su equipo también está trabajando en el rediseño del sitio web, para incluir una tienda virtual en la que los interesados puedan adquirir los libros, ya sea en soporte papel o digital Esta innovación no solo permitiría reducir las tiradas, sino que permitiría comercializar los libros electrónicos en todo el mundo, evitando los elevados costos de logística y trasporte.

A modo de cierre de este apartado, podemos concluir que EDUNTREF es una editorial pequeña que, aunque financieramente depende fuertemente de la Universidad, ha comenzado a dar pasos firmes en pos de una mayor autonomía editorial. Las iniciativas a las que nos hemos referido (en relación a los autores, a la apertura a nuevos lectores y mercados, a la racionalización de la distribución e impresión, a la inclusión de nuevos soportes) evidencian que los criterios editoriales le están ganando espacios a los criterios puramente 
académicos. Volviendo a los paradigmas editoriales en el marco de los procesos de internacionalización (ver arriba, Gazzera, 2014), EDUNTREF pareciera estar abandonando un perfil de exclusivo servicio a la Universidad y a sus académicos para convertirse progresivamente en agente promotora de la inclusión de nuevos lectores, autores y obras. Dada la dirección que están adoptando las políticas editoriales de EDUNTREF, es más que pertinente explorar entonces que sucede en relación a sus políticas de traducción.

\section{Políticas de traducción}

Diversos autores (Cf: Puccio y Ghio, 2014; Gastaldi y Grimaldi, 2016) afirman que la cuestión lingüística es de fundamental importancia para el éxito de los procesos de internacionalización de la educación. Esto tiene su correlato en el campo editorial, donde el intercambio internacional de obras también debe pensarse en relación a las lenguas. Para indagar acerca de las políticas de traducción, es necesario distinguir dos procesos: la intraducción -la compra de derechos para traducir obras en otros idiomas al español--, y la extraducción -la venta de derechos de autores argentinos para traducir y publicar sus obras en otros idiomas (Adamo, Añón y Wulichzer, 2009). Si bien ambos procesos son complementarios, distan de ser equivalentes. Como señala el informe editado en 2009 por la Fundación TyPA, históricamente, las editoriales argentinas privilegiaron la intraducción por sobre la extraducción, aún cuándo la difusión internacional del capital literario y cultural nacional depende de la segunda (Adamo, Añón y Wulichzer, 2009). Como veremos a continuación, las políticas de traducción implementadas por EDUNTREF confirman esta tendencia.

\section{a. Políticas de intraducción}

Los libros traducidos al castellano por EDUNTREF ${ }^{3}$ representan alrededor del $15 \%$ de la totalidad de obras del catálogo. Se trata principalmente de obras ensayísticas en el campo de las artes o humanidades, publicadas originalmente en diversas lenguas entre las que se destacan las denominadas centrales ( 8 obras traducidas del francés, 2 del alemán), semicentrales ( 2 del italiano) o periféricas ( 2 del polaco), que sumadas duplican a las obras traducidas del inglés (6) (Cf. Heilbron, 2010).

Según relata la directora editorial, algunos de los títulos que se han traducido fueron propuestos por áreas o departamentos de la Universidad. Tal es el caso por ejemplo de las obras de Gramsci y Grimm, traducidas para la colección de Teoría Literaria por sugerencia del director de la maestría en Estudios Literarios Latinoamericanos. Para estos trabajos, son los mismos académicos que seleccionan la obra los que proponen a un traductor, que puede no ser un traductor profesional, sino un "traductor ocasional" (Sapiro, 2008), es decir, un especialista que proviene del ámbito universitario y que posee un amplio dominio de los contenidos de la obra y del autor (por ejemplo, el traductor seleccionado para traducir a Grimm es un investigador del CONICET en el área de Literatura). 
Entre los libros traducidos, el caso de Cine Expandido (escrito por el autor norteamericano Gene Youngblood) reviste especial importancia ya que abrió la puerta a un proceso alternativo de selección de obras, en el que subyace una verdadera política. Linares atribuye el éxito comercial del título a su singularidad:

Un libro que fue muy buscado y que el año pasado [2016] tuvimos que reimprimir porque se había agotado es Cine Expandido de Youngblood...es un libro que no se había publicado nunca en castellano y por eso tuvo mucha demanda, es un libro de culto (2017).

A partir de esta experiencia, se propuso incorporar traducciones de otros libros que nunca hubieran sido traducidos al castellano. Esto es una política editorial y de traducción fuerte, ya que como explica Venturini (2016), la apuesta por lo nuevo es un camino para que el catálogo logre su propia idiosincrasia. Sin embargo, Venturini aclara que la "importación de lo nuevo" nunca es una novedad absoluta, ya que "siempre tiene un respaldo dado por diferentes actos de legitimación previa en otros campos y mercados editoriales" (Ibíd.) Por eso, la selección de títulos depende de un trabajo de investigación desarrollado en conjunto con académicos especializados.

\section{b. Políticas de extraducción}

Hasta el momento, EDUNTREF no ha comercializado los derechos de autores nacionales para traducir sus obras a otros idiomas. Si bien participó enviando algunos libros físicos a la Feria del Libro de Frankfurt 2010 (cuando Argentina fue país invitado), no se utilizó esta oportunidad para la venta de derechos. La directora editorial sostiene que hay obras del catálogo que tienen potencial de venta en el exterior, como ser los de historia del peronismo, o algunos títulos de teoría literaria. Pero, como bien señala, la venta de derechos depende de la participación en las ferias internacionales, ya que son el lugar indicado para hacer las gestiones pertinentes.

La débil presencia de EDUNTREF en las ferias internacionales se origina, según la directora, en una suerte de "mito" respecto a qué es adecuado para una editorial universitaria: "esto es parte del prejuicio de las editoriales universitarias, que piensan que las ferias internacionales son para la edición comercial, y que la edición universitaria no tiene nada que ver con la edición comercial". Nuevamente, la tensión entre las lógicas académicas y editoriales emerge como condicionante, en este caso para la difusión del pensamiento y la obra académica propia.

\section{Conclusión}

A partir de lo expuesto, se puede postular que EDUNTREF está en el proceso de construcción de una política editorial propia, marcado fuertemente por la incorporación de la figura de director editorial al equipo de trabajo, quien implementó iniciativas que apuntan 
a sumar una perspectiva comercial e innovaciones técnicas a prácticas previamente basadas en criterios exclusivamente académicos. Este proceso de cambio resulta un terreno fértil para consolidar un perfil editorial más comprometido con la internacionalización de los programas educativos que se da en el seno de la institución madre, especialmente si la pensamos como acciones al servicio de la promoción y democratización del conocimiento, tanto a nivel local como internacional.

Las políticas impulsadas por la nueva gestión manifiestan un interés por construir una editorial inclusiva, atenta al lector y preocupada por diversificar su catálogo, para así llegar a un público más amplio. Sin embargo, internacionalizar la educación significa también incluir la dimensión internacional en lo local, y difundir lo propio fronteras afuera. Probablemente uno de los mayores desafíos de EDUNTREF sea trabajar en pos de la incorporación de diversidad de voces extranjeras y de la apertura de las obras locales al exterior. En este sentido, sorprende que los programas de estudio más internacionalizados, aquellos vinculados a la diversidad cultural o a las relaciones internacionales, no promuevan una mayor publicación de autores extranjeros. Asimismo, también llama la atención la ausencia de autores brasileños en el catálogo, sobre todo teniendo en cuenta que la universidad tiene más estudiantes provenientes de Brasil que el promedio nacional ${ }^{4}$.

Pensar en un intercambio más fluido con Brasil podría ser un punto de partida interesante para una mayor internacionalización del catálogo. No solo porque es un mercado educativo en crecimiento, sino porque la cercanía ideológica y cultural permite un fecundo intercambio académico. Como señala el informe de la Fundación TyPA,

En cuanto a la venta de derechos para la traducción propiamente dicha, el potencial diferencial del Brasil se refleja, sobre todo, en el intercambio de textos de no ficción: libros de excelente calidad académica que son difíciles de traducir a lenguas europeas, sí despiertan interés y son traducidos en Río o en San Pablo (Adamo, Añón y Wulichzer, 2009, p. 73-74).

Una historia similar y el haber sufrido los avatares de las mismas crisis económicas y políticas, hacen que los campos de producción (en el sentido que le atribuye Bourdieu, 2002) y de recepción a un lado y otro de la frontera no sean tan dispares.

Algunas de las estrategias que la editorial ha implementado, o está en proceso de implementar, son claves a la hora de pensar en los mercados internacionales. En relación al soporte, Adamo, Añón y Wulichzer indican que los libros académicos son los que más se benefician de las innovaciones tecnológicas: "Los costos más baratos de un e-book y, sobre todo, la posibilidad de hacer llegar este tipo de contenidos a los lectores especializados, en cualquier lugar del mundo abren un panorama lleno de promesas" (Adamo, Añón y Wulichzer, 2009, p. 69). Asimismo, el interés de la editorial por participar de ferias internacionales es un paso fundamental en un proyecto de expansión fronteras afuera.

En conclusión, la política editorial que está construyendo EDUNTREF conlleva oportunidades potenciales para internacionalizar su catálogo. Avanzar en esta dirección dependerá de los recursos financieros, humanos y tecnológicos que la Universidad esté dispuesta a invertir para reposicionar a su editorial en el mercado local e internacional. 


\section{Notas}

1. Disponible en http://untref.edu.ar/wp-content/uploads/2013/04/INFORME-COOPE RACI\%C3\%93N-2015-FINAL-1.pdf

2. Además de la producción monográfica, EDUNTREF cuenta con tres publicaciones periódicas: Methateoría-Revista de filosofía e historia de la ciencia (de publicación semestral), los Cuadernos de Políticas Culturales-Indicadores Culturales (anuales) y la Revista de Estudios sobre Genocidio (semestral).

3. No se incluyen en este análisis los libros traducidos al castellano que corresponden a la colección Estudios sobre Genocidio, coeditada con Prometeo.

4. Según datos obtenidos a partir del proyecto de investigación "Política lingüística e internacionalización de la educación superior. Análisis del tratamiento de la cuestión lingüística en universidades de Argentina y Brasil” (2016-2017, Secretaria de Investigación y Desarrollo, UNTREF).

\section{Referencias bibliográficas}

Adamo, G., Añón V. y Wulichzer L. (2009). La extraducción en la Argentina. Venta de derechos de autor para otras lenguas. Un estado de la cuestión 2002-2009. Buenos Aires, Argentina: Fundación TyPA.

Bourdieu, P. (2002). Las condiciones sociales de la circulación internacional de las ideas. Actas de la investigación en ciencias sociales, 145, p. 3-8.

Bourdieu, P. (1999). Una revolución conservadora en la edición. Actas de la investigación en ciencias sociales, 126/127, p. 3-28.

Catálogo EDUNTREF 2011, 2012, 2013, 2014, 2015 y 2016.

De Sagastizábal, L., Rama C. y Uribe R. (2006). Las editoriales universitarias en América Latina. Bogotá, Colombia: IESALC - CERLALC.

Gastaldi M. y Grimaldi E. (comps.) (2016). Políticas lingüísticas y lenguas extranjeras en el Nivel Superior. Santa Fe, Argentina: Universidad Nacional del Litoral.

Gazzera, C. (2014). Libros y Universidad. Universidade em Debate, 2 (1), p. 60-64.

Heilbron, J. (2010). Structure and Dynamics of the World System of Translation. Ponencia presentada en el Simposio Internacional de la UNESCO Translation and Cultural Mediation, February 22-23.

Knight, J. (2005). “Un modelo de internacionalización: Respondiendo a nuevas realidades y retos”. En H. De Wit, I. Jaramillo, J. Gacel-Ávila y J. Knight (Ed.), La dimensión internacional de la educación superior en América Latina. Washington D.C., EEUU: Banco Mundial, p. 1-38.

Puccio D. y Ghio E. (comps.) (2014). Las lenguas extranjeras y los desafíos de la internacionalización en la educación. Santa Fe, Argentina: Universidad Nacional del Litoral.

Sapiro, G. (2008). «Normes de traduction et contraintes sociales». En A. Pym, M. Shlesinger y D. Simeoni (Ed.), Beyond Descriptive Translations Studies. Investigations in homage to Gideon Toury, p. 199-208. Filadelfia: John Benjamins Publishing Company. 
Sapiro, G. (2010). “Editorial policy and translation”. En Y. Gambier y L. van Doorslaer (Ed.), Handbook of Translation Studies, p. 32-38. Filadelfia: John Benjamins Publishing Company.

Stukalsky, D y Gazzera, C. (2013). El libro universitario y su internalización. Recuperado de http://www.reun.librouniversitario.com.ar/documentos/LIBRO_UNIVERSITARIO _SU_INTERNACIONALIZACION.pdf

Willson, P. (2013). La traducción y sus discursos: apuntes sobre la historia de la traductología. Exlibris, 2, p. 82-95.

Venturini, S. (2016). ¿Qué es una política de traducción? Sobre editoriales literarias recientes de Argentina. Ponencia presentada en el II Coloquio Argentino de Estudios sobre el Libro y la Edición. Córdoba, 21 al 23 de septiembre de 2016.

\begin{abstract}
This paper explores the publishing policies of Editorial de la Universidad de Tres de Febrero (EDUNTREF) and, within these, focuses on their translation policies and their links with the local and international university activity of the UNTREF. Two sources of data have been used: catalogs of publications for the period 2011-2016 and an in-depth interview with the publishing director. The results obtained allow us to delineate the main characteristics and policies of the publishing house (following de Sagastizábal, 2006) and invite us to reflect on its role as a democratizing agent of knowledge within the process of internationalization of the University
\end{abstract}

Keywords: University Presses - Publishing Policy - Translation - Catalogues - Internationalization - Higher Education.

Resumo: O presente artigo explora as políticas editoriais do Editorial de la Universidad de Tres de Febrero (EDUNTREF) e, dentro delas, enfoca as políticas de tradução e suas ligações com a atividade universitária local e internacional do UNTREF. Para isso, trabalhamos com duas fontes de dados: catálogos de publicações para o período 2011-2016 e uma entrevista em profundidade com seu diretor editorial. Os resultados obtidos permitem delinear as principais características e políticas da editora (seguindo de Sagastizabal, 2006) e nos convidam a refletir sobre o papel da editora como agente democratizante do conhecimento no marco do processo de internacionalização da Universidade.

Palavras chave: Editoras Universitárias - Política Editorial - Tradução - Catálogos - Internacionalização - Ensino Superior.

[Las traducciones de los abstracts fueron supervisadas por el autor de cada artículo] 